Portland State University

PDXScholar

\title{
Effects on L1 During Early Acquisition of L2: Speech Changes in Spanish at First English Contact
}

\author{
Christina E. Gildersleeve-Neumann \\ Portland State University, cegn@pdx.edu \\ Elizabeth D. Peña \\ University of Texas at Austin \\ Barbara L. Davis \\ University of Texas at Austin \\ Ellen S. Kester \\ University of Texas at Austin
}

Follow this and additional works at: https://pdxscholar.library.pdx.edu/sphr_fac

Part of the Bilingual, Multilingual, and Multicultural Education Commons, and the Speech and Hearing Science Commons

Let us know how access to this document benefits you.

\section{Citation Details}

Christina E., G., Elizabeth D., P., Davis, B. L., \& Kester, E. S. (2009). Effects on L1 during early acquisition of L2: Speech changes in Spanish at first English contact. Bilingualism: Language \& Cognition, 12(2), 259-272. doi:10.1017/S1366728908003994

This Article is brought to you for free and open access. It has been accepted for inclusion in Speech and Hearing Sciences Faculty Publications and Presentations by an authorized administrator of PDXScholar. Please contact us if we can make this document more accessible: pdxscholar@pdx.edu. 
RESEARCH NOTE

\section{Effects on L1 during early acquisition of L2: Speech changes in Spanish at first English contact*}

\author{
CHRISTINA E. GILDERSLEEVE-NEUMANN \\ Portland State University \\ ELIZABETH D. PEÑA \\ BARBARA L. DAVIS \\ ELLEN S. KESTER \\ The University of Texas at Austin
}

\begin{abstract}
Spanish phonological development was examined in six sequential bilingual children at the point of contact with English and eight months later. We explored effects of the English vowel and consonant inventory on Spanish. Children showed a significant increase in consonant cluster accuracy and in vowel errors. These emerging sequential bilingual children showed effects of English on their first language, Spanish. Cross-linguistic transfer did not affect all properties of the phonology equally. Negative transfer may occur in specific areas where the second language is more complex, requiring reorganization of the existing system, as in the transition from the Spanish five-vowel to the English eleven-vowel system.
\end{abstract}

\section{Introduction}

Phonological systems vary widely across languages in systematic ways (Maddieson, 1984), providing a background for considering the effects of early bilingualism on the course of language acquisition. Early sequential bilinguals are children who begin learning language in a monolingual environment (their home language, or L1), and first receive regular exposure to a second language (the community language, or L2), when they enter school, typically between the ages of 3 and 5 (McLaughlin, 1984; Anderson, 2004; Paradis, 2005). In the U.S., sequential bilingual children form a large subset of bilingual children. A defining characteristic of sequential bilinguals is their use of what they have learned about language in L1 to gain language skills in L2 (McLaughlin, 1984). Early sequential bilinguals begin acquisition of their second language before their first language is completely established.

In the current study, we explore the effect of L2 (English) on the L1 (Spanish) phonological system. We analyze vowels, consonants, and syllable and word shapes produced by six sequential Spanish-English bilinguals. These children were from home environments where standard Mexican Spanish was spoken and were first regularly exposed to English when they began attending

\footnotetext{
* The data for this study were collected while the first author was at The University of Texas at Austin. Funding for data collection was provided to the first author by a Department of Education Leadership Training Grant (\#H325D000029) awarded to Thomas Marquardt, Department of Communication Science and Disorders, The University of Texas at Austin. We would like to thank the reviewers for their helpful suggestions.
}

an English-speaking Head Start classroom between the ages of 3 and 4 . We compared single-word samples of the children's L1 productions at two time points: at the beginning of the school year when they were first introduced to English (T1), and after 8 months of regular L2 exposure (T2) in their school setting.

\section{Spanish and English phonology}

To understand the possible effects of English on Spanish, phonologies of standard Mexican Spanish and standard American English are compared. ${ }^{1}$ Generally, English is more complex in vowel and syllable structure relative to Spanish. There are fewer consonant (18 vs. 24) and vowel (5 vs. 11) phonemes in Spanish. Consonants of English and Spanish are similar, with both languages containing $/ \mathrm{b} \mathrm{p} \mathrm{d} \mathrm{t} \mathrm{g} \mathrm{k} \mathrm{m} \mathrm{n} 1 \mathrm{t} \int \mathrm{s} \mathrm{f} \mathrm{j} \mathrm{w/.}{ }^{2}$ But there are phonemic and phonetic differences in these shared consonants. For example, $/ \mathrm{t} /$ and $/ \mathrm{d} /$ are produced using dental placement in Spanish but are produced on the alveolar ridge in English. In Spanish, voiced stops are frequently produced as a homorganic approximant $(/ \mathrm{b} \mathrm{d}$ $g /$ as $\left[\begin{array}{lll}\beta & \partial & \gamma\end{array}\right]$, except after a nasal or a pause. Spanish

1 There are many dialects of Mexican Spanish and American English. Presented are the standard versions of these dialects which describe the dialects spoken to the children in this study. For ease of reading, we refer to these as Spanish and English from this point in the paper forward.

2 We classify the prevocalic glides /j, w/ as consonants and divide the Spanish and English phonemes into the two broad categories of consonants and vowels. Post-vocalic glides are treated as the latter half of a diphthong vowel. 
consonant phonemes with no equivalent English phoneme include / $\mathrm{x}$ j $\mathrm{r} \mathrm{r} /$. Spanish phonology does not include the English consonant phonemes / $\mathrm{j} v \theta \mathrm{z} \int 3 \mathrm{~h} d 3 \mathrm{I} /$. In Spanish, [v] can occur as an allophone of $/ \mathrm{b} /$, and [h] can occur as an allophone of /x/ (Goldstein, 2001).

Standard Spanish contains five vowels, /i e a o u/, while Standard American English contains eleven, /i I $\mathrm{e}^{\mathrm{I}}$ $\varepsilon æ \Lambda 3^{r} \mathrm{a} \mathrm{o}^{v} \mathrm{u} \mho /$. Spanish does not employ the phonemic tense-lax contrast of English, nor do the two Spanish mid-vowels have the allophonic diphthong quality of the mid-front $\left(\mathrm{e}^{\mathrm{I}}\right)$ and mid-back $\left(\mathrm{o}^{v}\right)$ vowels of English. Many English phonemic vowel contrasts have allophonic status in Spanish. For instance, the Spanish /i/ is between the American English /i/ and / $/$ / in vowel quality and duration. The Spanish vowels /u o e/ differ in vowel quality from their English counterparts (Bradlow, 1995). Spanish has no equivalent to the English mid-central $/ \Lambda /$, or to the low front and low back vowels $/ æ /$ and $/ \mathrm{a} /$. The vowel quality of the Spanish low central vowel /a/ is between these three vowels.

Permissible syllable and word shapes differ markedly between Spanish and English as well. In Spanish, unlike in English, there are few complex word-final clusters, and only the coronal consonants $/ \mathrm{n} \mathrm{s} \mathrm{ld} /$ are likely to appear word-finally. In general, consonant clusters in every word position are more limited in type and frequency in Spanish than in English, although multisyllabic words occur with much greater frequency.

\section{Phonological development}

As a framework for exploring the effects of English exposure on Spanish, we provide a brief overview of phonological development. Unless stated otherwise, our discussion of phonological development refers to the sounds and sound patterns that children produce. Monolingual children across languages produce highly similar sound and sequence properties until approximately 18 months of age. They have been described as producing a consistent "motor core" of similar patterns, including stops, nasals, and glides at the labial and alveolar place of articulation, and low front and central vowels (MacNeilage, Davis, Kinney, and Matyear, 2000). In addition, children in a variety of language environments produce utterances with simple syllable and word shapes, primarily $\mathrm{CV}$ and $\mathrm{CVCV}$, and infrequent use of clusters and final consonants (Oller and Eilers, 1982; Vihman, Ferguson and Elbert, 1986; Anderson and Smith, 1987; Boysson-Bardies and Vihman, 1991; Davis and MacNeilage, 1995; Gildersleeve-Neumann, 2001; Goldstein and Cintrón, 2001).

Some aspects of early phonological development are language-specific. By age 2, Spanish-learning children are reported to have mastered production of the Spanish vowel system (Goldstein and Pollock, 2000), earlier than reported for English learners (Stoel-Gammon and Herrington, 1990). This earlier vowel mastery in Spanish than English has been attributed to the less complex Spanish vowel system (Goldstein and Pollock, 2000). Between ages 2 and 5, utterances produced by typicallydeveloping monolingual children increasingly reflect their ambient language phonology. Most monolingual Spanishlearning children demonstrate a fairly complete Spanish phonological system in their speech by age 4 (Linares, 1981; Jimenez, 1987; Acevedo, 1993; Goldstein, 2001; Nuñez-Cedeño, 2007). At 4, only cluster reduction, final consonant deletion, and unstressed syllable deletion are typically observed at error rates greater than $10 \%$ (Goldstein and Iglesias, 1996; Yavaş and Goldstein, 1998; Goldstein and Washington, 2001). By age 5, Spanishspeaking children are reported to have mastered the production of all Spanish consonants except $/ \mathrm{r} /$, which is mastered by approximately $85 \%$ of children at this age (Acevedo, 1993). Similar ages for accurate production of late-developing phonemes and syllable shapes have also been observed in monolingual English learners (StoelGammon and Dunn, 1985; Porter and Hodson, 2001).

Often the phonological properties that take the longest to master are those considered articulatorily more complex or less frequent in the language. In English, monolingual children accurately produce clusters, some fricatives, affricates, and liquids later in development. In Spanish, complex clusters, the tap, and the trill emerge later in phonological development. An example of the potential role of frequency in the adult language is seen in development of final consonants in Spanish. Final consonant deletion persists for a longer period in Spanish-learning than in English-learning children. This developmental difference has been attributed to fewer final consonants in Spanish than in English (Anderson and Smith, 1987; Morales-Front, 2007).

Phonological development is most frequently described for children learning one language. However, some literature is available examining transfer effects in SIMULTANEOUS bilinguals. This literature suggests that some aspects of the development of the bilingual child's phonological system differ, resulting in slightly different rates of phonological development and error patterns for bilinguals compared to monolinguals (Goldstein and Washington, 2001; Kehoe and Lleó, 2003; GildersleeveNeumann, Kester, Davis, and Peña, 2008). Goldstein and Washington (2001) observed language-specific error patterns in single-word productions in 12 four-yearold Spanish-English simultaneous bilingual children. Transfer of phoneme properties from one language to the other has also been reported. Gildersleeve-Neumann et al. (2008) found that the English of 33 three- and fouryear-old simultaneous bilingual Spanish-English children contained a greater number of occurrences of spirantization and final consonant deletion than did the English 
of their monolingual peers. The authors proposed that there was an effect of the children's Spanish phonological system on their English. Kehoe and Lleó (2003) examined syllable-shape acquisition in five monolingual German, three monolingual Spanish, and three bilingual GermanSpanish toddlers longitudinally. The bilingual children demonstrated earlier emergence of complex syllable shapes in Spanish when compared to the monolingual Spanish children, suggesting the effect of the more complex syllable shapes of German in the bilingual children.

Two longitudinal case studies of simultaneous bilinguals have also proposed effects of the vowels of one language on the vowels of the other language. In one study, three bilingual (Spanish-German) children were similar in the development of stressed vowels in Spanish to two monolingual Spanish children, but their development of stressed vowels in German was delayed compared to the three monolingual German children (Kehoe, 2002). This difference was suggested to result from the greater complexity of the German vowel system in comparison to the Spanish vowel system. Johnson and Lancaster (1998) noted that vowel productions in a simultaneous bilingual Norwegian-English toddler were highly variable, particularly in the use of tense-lax distinctions. These findings in two different language pairs suggest that there will be a greater number of errors and a slower timeframe for development of accurate production of vowels than in the less contrastive language.

Research on sequential bilinguals has shown different patterns of influence on consonant development between languages. Holm and Dodd (1999) documented continued effects of English phonology on the Cantonese in two Cantonese-speaking children from $2 \frac{1}{2}$ to $3 \frac{1}{2}$ years of age, in the process of learning English. The children were reported as having typical sound patterns in Cantonese prior to English exposure. After exposure to English, atypical patterns such as initial consonant deletion and voicing were noted in both English and Cantonese. In contrast, Anderson (2004) found little transfer of consonant properties between languages in longitudinal case studies of five sequential preschoolaged bilingual children from a variety of home language environments (Korean, Russian, French) learning English as their L2. She established similar developmental levels for children in both language environments, with appropriate language-specific consonant phonetic inventories for each child. In general, consonant error patterns appeared specific to each language environment, although Anderson noted limited transfer of phonetic information from one language to the next. Examples of transfer include the erroneous production of $[\theta]$ in French by the French-English sequential bilingual, and the erroneous interdental production of /s/ in English by the three Korean-English bilingual children (the Korean $/ \mathrm{s} /$ is produced dentally).

\section{Sequential bilingualism and language competition}

The UNIFIED COMPETITION MODEL (MacWhinney, 2005) provides a framework to examine transfer of speech properties in sequential bilingual language learning. Within this framework, language learning is conceptualized as learning to process and decode information. Information that is frequent and reliable is proposed to have strong cue strength and to be acquired more easily. In a dual-language environment, there will necessarily be competition between linguistic input of the two languages, causing a shift in cue strength across the two systems. Thus, frequent and reliable speech cues in both languages will be strengthened and lead to rapid development or positive transfer in both languages. Negative transfer effects are likely to be seen when low frequency forms differ in each language and distribution of the cues across both lowers their overall frequency in the input affecting both languages. Consistent with a "languages-in-contact" (Döpke, 2000) perspective, forms that have subtle differences between them in the two languages may also be subject to transfer effects. For example, in English, /I/ and /i/ are distinct vowel phonemes, but in Spanish, $/ \mathrm{I} /$ is an allophonic variant of $/ \mathrm{i} /$.

A child in a bilingual environment must sort out the language-specific input, eventually developing skill to communicate accurately in both languages. In sequential bilinguals, it is likely that during early L2 development, children initially utilize the phonological knowledge from their first language to produce sounds in their second language, more like an adult learner. But children who become sequential bilinguals in the first five years of life are likely still developing aspects of their L1 phonology and are still mastering speech production capabilities for their L1. Hence, it is possible that the L2 information (or cues) will affect continued development of L1.

Because Spanish and English have many similar consonant properties, particularly for consonants produced by the majority of preschool-aged children, consonant cue reliability in preschool sequential bilinguals is expected to be strong. Sequential bilingual children may rely successfully on similar consonants of Spanish in their acquisition of English consonants, with more fine-grained phonetic distinctions, such as VOT differences, slowly gaining accuracy. Complex syllable shapes differ between Spanish and English, with final consonants and complex clusters less frequent, and multisyllabic words more frequent, in Spanish. These unambiguous differences in syllable shapes are not predicted to result in negative transfer from English to Spanish. In addition, many consonants that differ between Spanish and English, such as rhotics, clearly differ in acoustic and in articulatory properties. Complex consonants and syllable shapes that differ between Spanish and English are primarily laterdeveloping. Because of their differences and the fact that they are not likely to be mastered in 3-and 4-year-olds, 
it is not expected that learning complex consonants or syllable shapes in English will result in negative transfer to complex consonants or syllable shapes in Spanish.

In contrast to the consonant systems, the Spanish and English vowel systems differ considerably. As a result, cue reliability for Spanish vowels may not be as strong as for consonants for a sequential bilingual child learning English as L2. The five Spanish vowels must be mapped onto eleven English vowel phonemes, likely requiring conceptual reorganization and resulting in lower cue reliability when Spanish-speaking children are learning English. To illustrate, MacWhinney (2005) suggests that for vocabulary the greatest transfer-produced errors may occur when the L1 blocks a contrast that is necessary in L2. He proposes that this lack of contrast necessitates conceptual reorganization in the sequential bilingual. We propose that this conceptual reorganization is the case for phonology as well. Because Spanish has fewer vowel phonemes, Spanish-speaking children learning English will need to recognize and produce English phonemic distinctions that are allophonic or do not exist in Spanish.

Previous case studies of simultaneous bilinguals suggest an effect of low cue reliability for bilingual vowel development when languages differ in vowel complexity. The result, in simultaneous bilinguals, appears to be slower acquisition of the more complex vowel system (Kehoe, 2002), or variability of vowel accuracy use in the two languages (Johnson and Lancaster, 1998). It is not known, however, if low cue reliability across languages has an effect on L1 development in sequential bilinguals.

Analysis of how the introduction of the L2 English sound system affects the L1 Spanish sound system in sequential bilingual children exposed initially to Spanish can further test the influence of cue reliability on L1. We examined Spanish in preschool-aged children at the point when English was first introduced, and after eight months of English exposure. Consistent with MacWhinney's (2005) unified competition model, we anticipated small effects of English exposure on areas of little ambiguity between the languages. Consonant and word-shape error patterns specific to Spanish or that exist in both Englishand Spanish-learning children were hypothesized to not be affected strongly by English exposure. Developmental patterns (or errors) were hypothesized to continue decreasing as they would in monolingual Spanish learners. We also hypothesized that exposure to English would affect the children's vowel system in Spanish, the area of greatest difference between the two languages. Productions of Spanish vowels are likely to be affected because of the overlapping nature of vowel phonemes and allophones in English and Spanish and because of the more limited vowel inventory in Spanish than in English. These effects were hypothesized to occur as increased vowel error pattern rates in Spanish.
Table 1. Gender and age (years;months) of participants. Standard Deviations are shown in parentheses.

\begin{tabular}{llll}
\hline \hline Child & Gender & Age at Time 1 & Age at Time 2 \\
\hline GH & Female & $3 ; 2$ & $3 ; 10$ \\
MV & Female & $3 ; 3$ & $3 ; 11$ \\
GV & Male & $3 ; 2$ & $3 ; 10$ \\
KS & Male & $3 ; 7$ & $4 ; 3$ \\
SR & Male & $3 ; 9$ & $4 ; 5$ \\
CV & Male & $3 ; 10$ & $4 ; 6$ \\
& Average & $3 ; 5(0 ; 4)$ & $3 ; 11(0 ; 4)$ \\
\hline \hline
\end{tabular}

\section{Method}

\section{Participants}

Picture naming responses were gathered from six children at a central Texas Head Start site where we conducted a larger study of bilingual Spanish-English phonological development in English (Gildersleeve-Neumann et al., 2008). These six children did not speak English when they entered the Head Start classroom in the fall. All six were from Mexican Spanish-only home environments and were described as developing speech typically. Typical speech and language development was established through researcher observation, parent report, and testing procedures, including performance on the Spanish versions of the Expressive and Receptive OneWord Picture Vocabulary Tests (Gardner, 1985, 1990), the Comprehension Subtest of the Stanford Binet Intelligence Scale (fourth edition) (Thorndike, Hagen and Sattler, 1986), and dynamic assessment procedures (Kester, Peña and Gillam, 2001). The average age of the children (2 females, 4 males) was 3;5 years at the study onset (range: $3 ; 2-3 ; 10)$. Table 1 shows ages at both data collection points.

\section{Data collection}

Single-word speech samples were collected in Spanish from these six children in the first month of their Head Start school year (T1) and eight months later, at the end of their school year (T2). Children attended school approximately four hours per day, providing 20 hours of English exposure per week. Productions of 45 words were analyzed, a total of 270 word types across the six children. Words were elicited with a picture identification task designed to include the consonants and vowels of Spanish in stressed syllables. At least three words for each Spanish phonemic monophthong were included, targeting the Spanish vowels /i e a o u/. Words of one to four syllables with varying syllable-shape complexity were included (see Appendix A). Words included items 
from the tests Assessment of Phonological Disabilities Spanish (Iglesias, 1978) and Assessment of Phonological Processes - Spanish (Hodson, 1986).

Fluent Spanish-speaking graduate student clinicians in speech-language pathology administered the picture naming task to the children at $\mathrm{T} 1$ and T2. Children were encouraged to produce words spontaneously but delayed imitation of the words was also accepted. A Marantz PMD-201 portable analog tape recorder and a Sony Lavaliere microphone were used to audio-record all speech samples.

\section{Data analyses}

The primary author transcribed all data phonetically. Phonetic transcriptions were entered for computer analysis using Logical International Phonetics Program, version 2.02 (LIPP, Oller and Delgado, 2000). Ten percent of the children's utterances were re-transcribed by a fluent English-Spanish bilingual with extensive child speech phonetic transcription experience. Mean inter-transcriber agreement was $95.5 \%$. Disagreements in transcription were discussed and the two transcribers reached mutual consensus on the final transcription used for analyses.

At each time point, independent analyses were completed to determine whether phonetic inventories of sounds produced were correct or incorrect. Independent analysis determined phonetic inventories of consonants, vowels, syllables, and word shapes. These results were analyzed descriptively, for the group and for individual children. Relational analyses were conducted to determine percent consonant accuracy (PCC, see Shriberg et al., 1997), percent vowel accuracy (PVC, see Shriberg, 1993), and rate of 22 phonological error patterns (see Appendix B). These error patterns were selected because of reported occurrence during development in children from a variety of language backgrounds (e.g., cluster reduction, final consonant deletion) and specific occurrence in Spanish speech development (e.g., tap error, trill error), and to provide a greater understanding of vowel errors in Spanish (e.g., vowel raising, vowel lowering). In addition, error patterns were analyzed to examine cross-linguistic effects because of their reported occurrence in English (e.g., gliding, glottal substitution). The frequency of these error patterns in the six children is shown in Table 2.

Ten of the phonological error patterns were found to occur at rates of less than $4 \%$ at $\mathrm{T} 1$ and $\mathrm{T} 2$ (cluster deletion, medial consonant deletion, stressed syllable deletion, unstressed syllable deletion, backing, gliding, glottal substitution, liquid simplification, nasal stopping, and large front/back vowel change). Because of their low frequency, these phonological error patterns were not analyzed further. Five other error patterns (final consonant deletion, spirantization, stopping, tap error, vocalization) changed by an average of two percentage points or fewer from T1 to T2. To control for Type I error, change over time in error patterns was compared statistically only for the seven error patterns meeting two criteria: (i) occurring at an average rate of $4 \%$ or greater at $\mathrm{T} 1$ or $\mathrm{T} 2$, and (ii) changing over time by at least two percentage points. Two of these error patterns were consonant substitution patterns (fronting, trill error), three were vowel substitution patterns (small front/back change, lowering, raising), and two affected syllable shapes (cluster reduction, initial consonant deletion).

Change over time was examined for PCC, PVC, and phonological error patterns using Wilcoxon signedrank test, the non-parametric equivalent of a dependent $t$-test, corrected in SPSS for multiple comparisons. PCC, PVC, and error patterns were independent variables, with time as the within-subjects factor. A significance level of $p=.05$ was adopted. Effect size was calculated and interpreted as $.10<r<.30=$ small effect, $.30<r<.50=$ moderate effect, $.50<r=$ large effect (Cohen, 1988). In addition, relational analyses were examined descriptively to provide detail regarding statistical results.

For PVC and phonological error patterns centered on vowels, only vowel errors that would negatively affect intelligibility were considered. For example, vowel differences perceptible to an English speaker because of tense-lax distinctions were not considered errors (e.g., tijeras /tixeras/ "scissors" produced as [tixeras]). Production of [ə] for /a/ in unstressed syllables was also not considered an error.

\section{Results}

\section{Phonemic inventory}

All six children were typically-developing preschoolers and produced the vast majority of sounds that occur as phonemes in Spanish. Children produced all of the vowels, most of the consonants and consonant allophones, and a variety of Spanish word shapes at both time points. In addition, many children produced English-influenced consonants and vowels at $\mathrm{T} 2$, but not at $\mathrm{T} 1$, consistent with our predictions.

\section{Consonant inventory}

At T1, four of the six children produced an inventory including all 18 consonant phonemes of Spanish while the other two did not produce one Spanish phoneme (child $\mathrm{GH}$ did not produce $/ \mathrm{t} \mathrm{j} /$ and child $\mathrm{GV}$ did not produce $/ \mathrm{r} /$ ). At $\mathrm{T} 2$, three children produced all 18 phonemes and three children did not produce one phoneme (GH and $\mathrm{GV}$ : $/ \mathrm{r} /$, SR:/n/). Allophones of Spanish phonemes were produced by all children in these single-word productions. They included [ð $\gamma \beta \lambda \mathrm{h} \mathrm{v}$ ] and were all produced at T1 and at T2. At T2, many phones not considered allophones in 
Table 2. Descriptive statistics and statistical comparisons for average phoneme accuracy and error pattern frequencies at both points in time and for change over time $(N=6)$.

\begin{tabular}{|c|c|c|c|c|c|c|c|}
\hline & \multirow[b]{2}{*}{ Time 1 Mean (SD) } & \multirow[b]{2}{*}{ Time 2 Mean (SD) } & \multirow[b]{2}{*}{ Change $\ddagger$ Mean (SD) } & \multicolumn{4}{|c|}{ Wilcoxon signed ranks } \\
\hline & & & & $z$ & $t$ & $p^{*}$ & $r$ \\
\hline \multicolumn{8}{|l|}{ Percent accuracy } \\
\hline Percent consonants correct & $77.7(5.0)$ & $75.3(2.7)$ & $-2.4(4.7)$ & -0.94 & 3.00 & .345 & -.272 \\
\hline Percent vowels correct & $93.1(1.7)$ & $87.2(5.5)$ & $-5.9(5.5)$ & -2.20 & 0 & $.028^{*}$ & -.636 \\
\hline \multicolumn{8}{|l|}{ Syllable-level errors } \\
\hline Cluster deletion & $0.0(0.0)$ & $0.0(0.0)$ & $n a$ & na $\dagger$ & na & na & na \\
\hline Cluster reduction & $44.0(23.5)$ & $39.6(24.4)$ & $4.4(2.3)$ & -2.02 & 0 & $.043^{*}$ & -.584 \\
\hline Final consonant deletion & $15.7(9.9)$ & $16.4(15.5)$ & $-0.7(20.1)$ & na & na & na & na \\
\hline Initial consonant deletion & $4.9(4.4)$ & $2.5(3.0)$ & $2.41(5.1)$ & -0.94 & 2.75 & .345 & -.272 \\
\hline Medial consonant deletion & $0.4(1.0)$ & $1.2(2.1)$ & $-0.8(2.5)$ & na & na & na & na \\
\hline Stressed syllable deletion & $1.1(0.9)$ & $2.5(2.3)$ & $-1.4(2.6)$ & na & na & na & na \\
\hline Unstressed syllable deletion & $1.3(1.6)$ & $2.9(4.0)$ & $-1.6(4.5)$ & na & na & na & na \\
\hline \multicolumn{8}{|l|}{ Consonant errors } \\
\hline Backing & $2.7(2.0)$ & $3.1(1.4)$ & $-0.4(2.3)$ & na & na & na & na \\
\hline Fronting & $5.1(3.2)$ & $2.8(2.0)$ & $2.4(2.9)$ & -1.57 & 1.50 & .116 & -.454 \\
\hline Gliding & $0.0(0.0)$ & $3.3(8.2)$ & $-3.3(8.2)$ & na & na & na & na \\
\hline Glottal substitution & $0.3(0.5)$ & $0.0(0.0)$ & $0.3(0.5)$ & na & na & na & na \\
\hline Liquid simplification & $3.3(8.2)$ & $3.3(8.2)$ & $0.0(12.7)$ & na & na & na & na \\
\hline Nasal stopping & $2.1(3.2)$ & $3.4(5.9)$ & $-1.3(3.3)$ & na & na & na & na \\
\hline Spirantization & $3.9(2.6)$ & $4.0(2.5)$ & $-0.1(2.0)$ & na & na & na & na \\
\hline Stopping & $6.0(4.6)$ & $6.3(2.5)$ & $-0.3(5.0)$ & na & na & na & na \\
\hline Tap error & $61.3(23.8)$ & $59.7(22.3)$ & $1.6(24.2)$ & na & na & na & na \\
\hline Trill error & $80.8(22.5)$ & $73.7(23.5)$ & $7.1(29.4)$ & -0.41 & 3 & .686 & -.117 \\
\hline Vocalization & $4.6(4.1)$ & $4.4(0.3)$ & $0.2(4.0)$ & na & na & na & na \\
\hline \multicolumn{8}{|l|}{ Vowel errors } \\
\hline Front/back change: Small & $5.4(1.7)$ & $8.5(3.8)$ & $-3.1(3.8)$ & -1.99 & 1 & $.046^{*}$ & -.575 \\
\hline Front/back change: Large & $0.5(0.8)$ & $0.3(0.7)$ & $0.3(0.7)$ & na & na & na & na \\
\hline Lowering & $8.1(4.3)$ & $14.0(8.4)$ & $-5.9(8.9)$ & -1.36 & 2 & .173 & -.393 \\
\hline Raising & $6.0(3.2)$ & $8.9(4.7)$ & $-2.9(2.8)$ & -1.99 & 1 & $.046^{*}$ & -.575 \\
\hline
\end{tabular}

$\ddagger$ Positive mean difference in Percent Correct measures indicates that the first group in the pair produced phonemes with a greater accuracy rate; positive mean differences in syllable-level and segmental error patterns measures indicates that the first group had a lower error pattern frequency.

${ }^{*} p<.05$

$\dagger$ Not applicable (na) indicates error patterns that were not statistically analyzed due to the low frequency of occurrence (less than $4 \%$ average occurrence at both points in time) or the low rate of change over time (less than 2 percentage point change).

Spanish were also produced - all demonstrated English influences; for example, children produced the English-

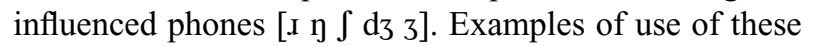
include the production of [I] by MV: [fores] for /flores/, [S] by GV: [le $\left.\int e\right]$ for /let $\int e /$, and [3] by SR: [3iko] for $/ \mathrm{t} \int \mathrm{iko} /$. SR was the only child who produced [d3] and [3]; all other English-influenced phones were produced by more than one child. Phones produced that were not influenced by Spanish or English were a lateralized /s/, produced by $\mathrm{GV}$ at both time points and by $\mathrm{KS}$ at $\mathrm{T} 2$.

\section{Vowel inventory}

All six children produced the five Spanish vowel phonemes / $\mathrm{i}$ e a o u/ at both time points. In addition, the children produced lax allophones of these vowels at both time points. The most frequent were $[I \varepsilon U]$. $[\Lambda]$ or $[ə]$ were often produced for /a/ in unstressed syllables. At T2 only, non-allophonic vowel phones were produced that reflect the influence of English. These were [3] and the rhotic [a. ]. All of these English-influenced vowel phones were produced by more than one child in Spanish. Examples 


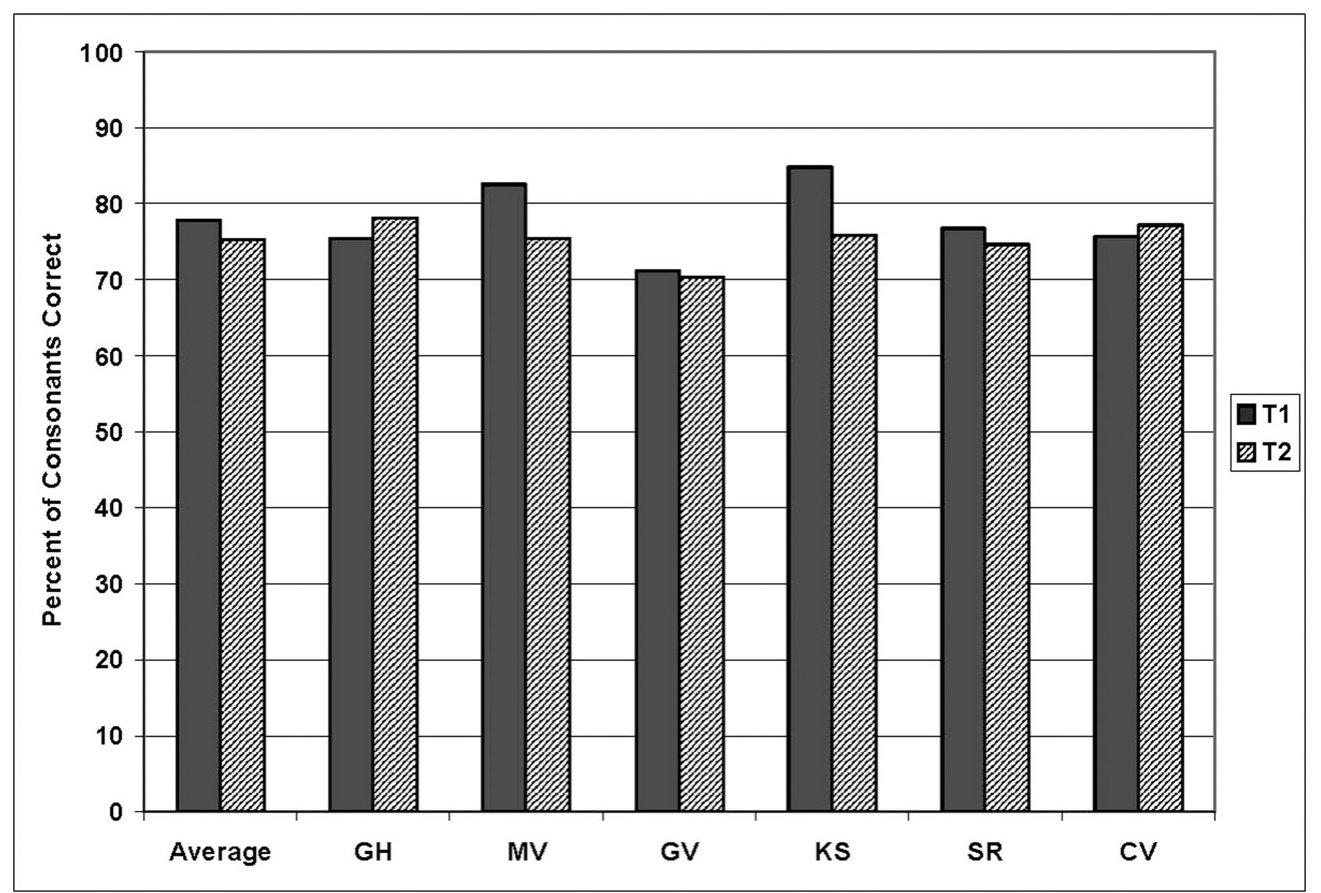

Figure 1. Group and individual percent of consonants correct (PCC) in Spanish at study onset (T1) and after 8 months of English exposure (T2).

include MV: [manə] for/mano/, GH: [pəo] for/pero/, KS: [martijo] for /martijo/, and GV: [pº] for /pero/.

\section{Phoneme accuracy and error patterns}

In addition to examining phonemic inventory, we examined change over time in single-word productions for 22 vowel, consonant, and word-shape error patterns. Table 2 shows descriptive and statistical results for all of these analyses. In general, error and accuracy rates were similar to those reported in previous research on bilingual Spanish-English children (Goldstein and Washington, 2001). Overall consonant accuracy and the frequency of most consonant error patterns did not change. These results are consistent with our hypotheses, as they occurred in areas of little ambiguity between the two languages, cluster reduction and trill errors; or areas where similar developmental error patterns have been noted cross-linguistically, such as consonant fronting. In contrast, significant changes in vowels were observed, resulting from a significant increase in vowel errors. Increases in vowel errors are consistent with our hypotheses due to the differences in the English and Spanish vowel systems. Specific findings for accuracy and error patterns are discussed below; details of statistical results are found in Table 2 .

\section{Consonant accuracy}

Percent of consonants correct (PCC) was compared at T1 and T2. Figure 1 shows change in PCC over time for each child and the average for the group. The average PCC for T1 was $78 \%$, ranging from $71 \%$ to $85 \%$. At T2, the average PCC had dropped slightly, to $75 \%$, with a narrower range of $70 \%-78 \%$. This decrease in consonant accuracy was not significant, $z=-0.94, p=.345$.

\section{Consonant error patterns}

Of the 11 consonant-level phonological error patterns originally explored, six occurred at average rates of greater than $4 \%$ (see Figure 2). Of these, fronting and trill error decreased at rates greater than two percentage points. Statistical analyses demonstrated no significant differences from $\mathrm{T} 1$ to $\mathrm{T} 2$ for consonant fronting $(\mathrm{T} 1=5.1 \%, \mathrm{~T} 2=2.7 \%)$ and trills $(\mathrm{T} 1=81 \%$, $\mathrm{T} 2=74 \%$ ). There was individual variation in some consonant error patterns. While there was virtually no change in consonant fronting, there was increased variability for stopping, tap, and trill errors. Stopping decreased by $2-7$ percentage points in three children, did not change in one child, and increased slightly in two (KS and GV). Error patterns affecting later-developing Spanish sounds showed greater variability. Three children decreased in trill errors, all by $25-30$ percentage points: KS produced trills with $50 \%$ accuracy at both points in time, GV never produced a trill correctly, and GH increased from $60 \%$ to $100 \%$ occurrence of trill error. Error rate for taps was above $40 \%$ for all children at both points in time but differed by child in change over time. Tap errors decreased by more than $20 \%$ for SR and GV, 


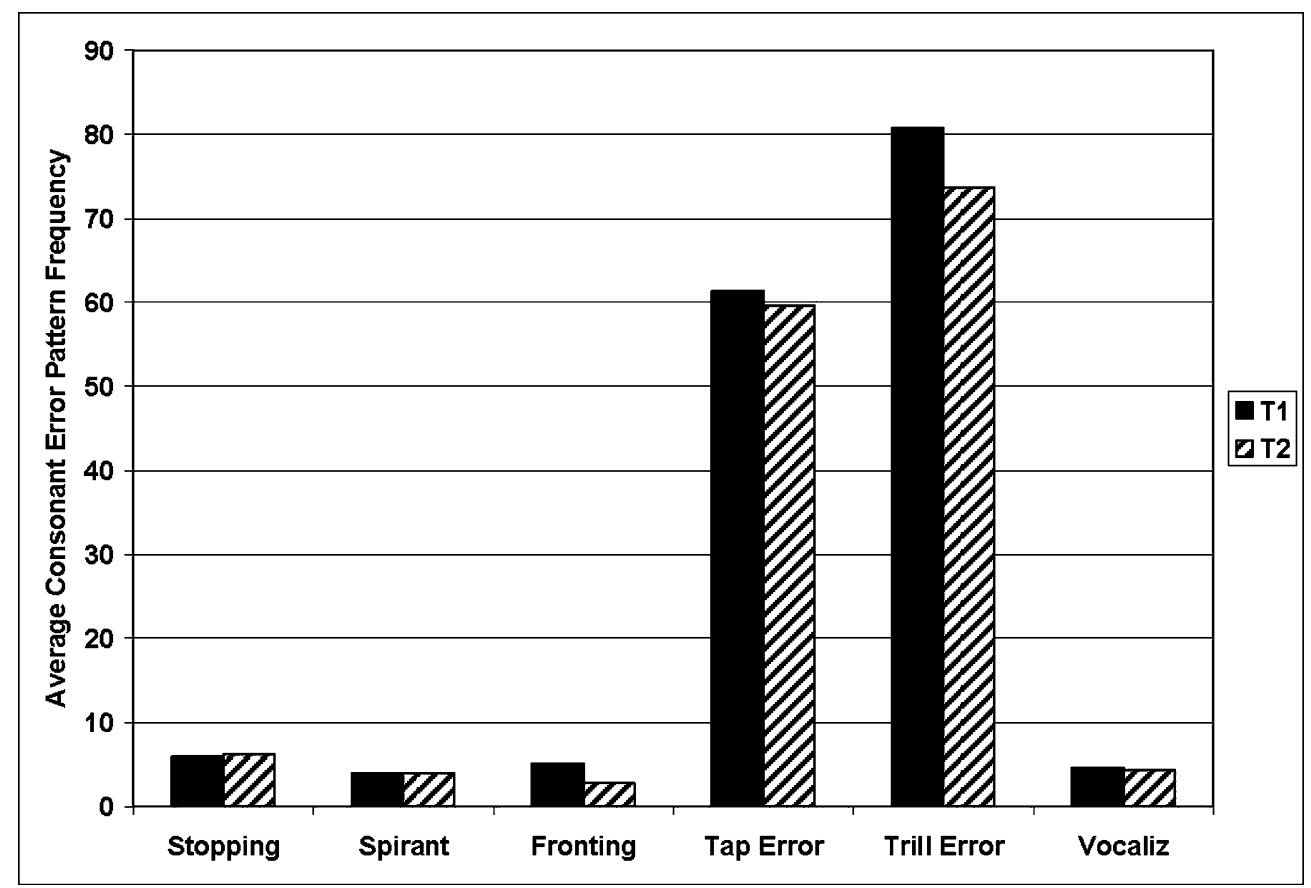

Figure 2. Average change over time in consonant error patterns occurring at rates of $4 \%$ or greater for the group $(\mathrm{N}=6)$.

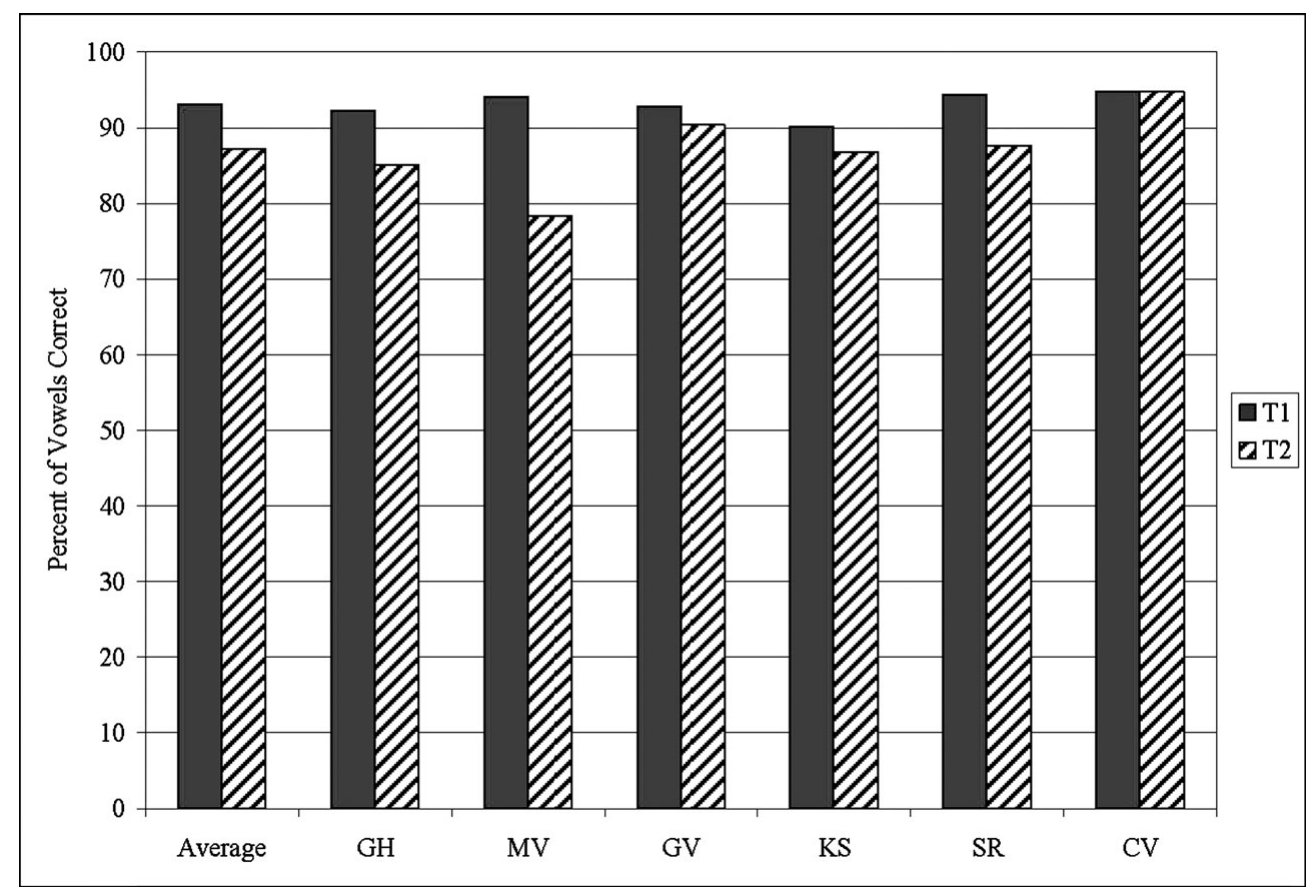

Figure 3. Group and individual percent of vowels correct (PVC) in Spanish at onset and after 8 months of English exposure.

did not change for CV and KS, and increased by $20 \%$ for $\mathrm{MV}$ and $\mathrm{GH}$.

\section{Vowel accuracy}

Percent of vowels correct (PVC) was compared at T1 and T2. Figure 3 shows PVC for Spanish vowels. PVC rates were significantly higher at $\mathrm{T} 1$ than at $\mathrm{T} 2, z=-2.20$, $p=.028$, with the average accuracy rate decreasing from $93 \%$ to $87 \%$. Only the oldest child, CV, maintained the same level of vowel accuracy. This change in PVC had a large effect size with an increase in vowel error rate over time for the group $(r=-.636)$. 


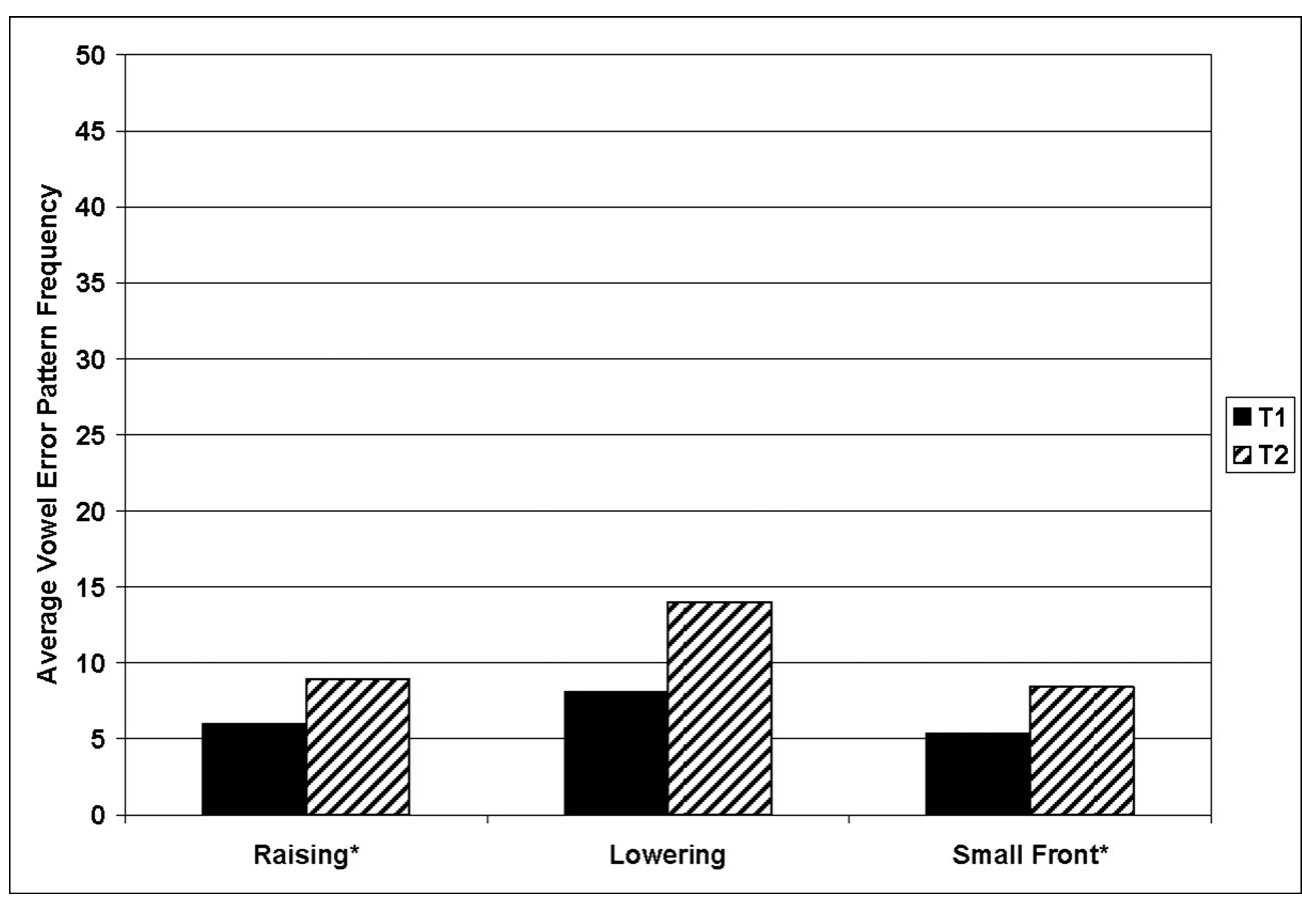

Figure 4. Average change over time in vowel error patterns occurring at rates of $4 \%$ or greater for the group $(\mathrm{N}=6)$. Note: ${ }^{*} p<.05$.

\section{Vowel error patterns}

Of the five vowel-level phonological error patterns explored, three occurred at rates greater than $4 \%$ and changed over time at rates greater than $2 \%$; these three vowel error patterns were further explored statistically. Figure 4 shows that all three increased in frequency and two (vowel raising and small front/back errors) increased significantly. Vowel raising increased from $\mathrm{T} 1(6 \%)$ to T2 $(9 \%), z=-1.99, p=.046$. Small front/back errors increased three percentage points, from $5.5 \%$ at $\mathrm{T} 1$ to $8.5 \%$ at $\mathrm{T} 2, z=-1.99, p=.046$. There was a large effect size for both of these vowel error patterns $(r=-.575)$. Five of the six children demonstrated this increase in vowel raising; only SR demonstrated a slight decrease, from $5 \%$ to $4 \%$. Small front/back errors increased for all children except SR, who decreased from $4 \%$ to $3 \%$.

While vowel lowering increased for the group from $8 \%$ to $14 \%$, the change was not significant. This nonsignificant change was accounted for by four children increasing rate of vowel lowering, KS decreasing (from $15.5 \%$ to $9.5 \%$ ), and SR lowering vowels with approximately the same frequency ( $4 \%$ at T1, 3\% at T2). Nevertheless, vowel lowering demonstrated a moderate effect size in error rate change.

\section{Syllable- or word-level patterns}

Three of the seven syllable- or word-level phonological process error patterns explored for change over time occurred at rates of $4 \%$ or greater at $\mathrm{T} 1$ or $\mathrm{T} 2$.
These three error patterns are shown in Figure 5. Error patterns with highest frequency were cluster reduction and final consonant deletion. Cluster reduction showed a significant decrease, $z=-2.02, p=.043$ with a large effect size $(r=-.584)$, and was observed in all six children. In contrast, final consonant deletion did not change, and averaged approximately $16 \%$ at both $\mathrm{T} 1$ and T2. At the individual level, however, there was high variability. Two children deleted final consonants at approximately equivalent rates at both time points, two children decreased (CV from 13\% to 6\% and MV from $33 \%$ to $0 \%$ ), and two children increased in their rate of final consonant deletion ( $\mathrm{GV}$ from $6 \%$ to $25 \%$, GH from $20 \%$ to $43 \%$ ). Initial consonant deletion decreased from $5 \%$ to $2.5 \%$, a non-significant change. At the individual level, initial consonant deletion decreased in four of the six children, never occurred in one child (CV), and increased in the sixth child (MV, from $0 \%$ to $6 \%$ ).

\section{Discussion}

These six children provide an example of the very early stages of Spanish-English sequential bilingualism (Grosjean, 1989; Baker, 2001). In general, error and accuracy rates were similar to reports in previous studies of Spanish-learning children and bilingual SpanishEnglish children (e.g. Goldstein and Washington, 2001). Our preliminary exploration of sequential bilingual 


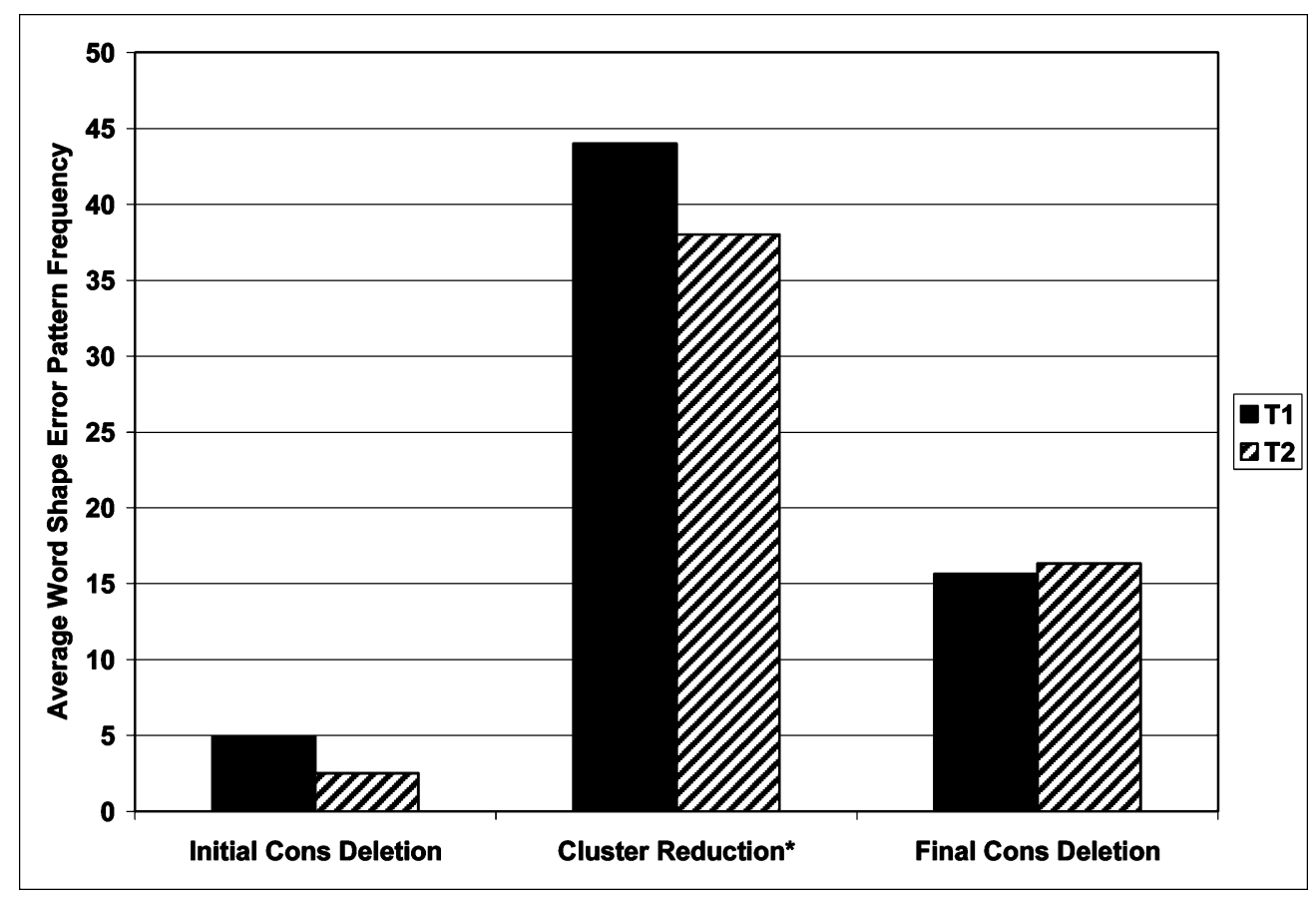

Figure 5. Average change over time in syllable shape error patterns occurring at rates of $4 \%$ or greater for the group ( $\mathrm{N}=6$ ). Note: ${ }^{*} p<.05$.

speech sound acquisition, based on single-word responses to pictures, suggests two issues of interest. In these preschool Spanish monolingual children, speech sound accuracy in L1 was affected by the introduction of their L2, English. The effect was observed in vowels particularly clearly. In addition, developmental errors typical for monolingual and simultaneous bilingual children also occurred in the children. These developmental errors continued to decrease or did not change in frequency even after exposure to L2. Some examples of these errors include the continued cluster reduction, final consonant deletion, and tap and trill substitution errors.

As predicted, and consistent with the unified competition model (MacWhinney, 2005), the most consistent pattern was the increase observed in Spanish vowel error patterns across the six children. As Table 2 shows, the variability of vowel accuracy in children increased over time, while variability or the standard deviation for consonant accuracy decreased. Monolingual 3- and 4-year olds are usually described as producing vowels accurately (Stoel-Gammon and Herrington, 1990; Goldstein and Pollock, 2000). Across the period of this study, there were significant decreases in vowel accuracy and corresponding increases in vowel front/back errors. These increases in vowel errors are consistent with our hypotheses, suggesting influence of L2 in areas of greater difference between the two languages. It appears that vowels are particularly vulnerable in Spanish-learning children at this age because of the potential reorganization created by exposure to a more complex English vowel system. Whether this increase in errors would happen in sequential bilinguals where the L2 had a less complex vowel system needs to be investigated further. Also warranting further investigation is whether similar effects occur in older monolingual Spanish-speaking children or adults who acquire English as L2.

Increase in vowel errors during speech acquisition is not frequently reported. Here in the emerging sequential bilinguals studied, an L1 with a smaller vowel system was negatively affected when acquiring an L2 vowel system with a more complex vowel inventory. Vowel errors have been reported in the more complex vowel system in simultaneous bilinguals (Johnson and Lancaster, 1998; Kehoe, 2002). Consistent with the competition model, we suggest that the vowel error increases observed in Spanish result from a loss of cue reliability for Spanish vowels in the introduction of additional English vowel input. It is possible that the lack of phonemic similarity in vowel systems between Spanish and English resulted in the negative transfer of English vowel properties to the children's L1, Spanish. Our findings, albeit with a small sample from only six children, suggest that the acquisition of an L2 with a larger vowel inventory may require reorganization of the child's underlying phonological system, affecting L1 vowel production in the sequential bilingual. This effect is likely related to reorganization 
of the vowel phonological system rather than loss. Research suggests that the effects of one phonological system on another are a temporary phenomenon, and that the child eventually develops complete and separate phonological systems (Genesee, 1989; Holm and Dodd, 1999; Goldstein, 2004).

Consonant error patterns presented a more variable picture in these six children. Overall, there was little obvious effect of English exposure on consonants or syllable-structure patterns of Spanish. For consonants, overall accuracy did not change, nor did the frequency of most consonant error patterns. Fronting, trill errors, and cluster reduction decreased in most children. These patterns are consistent with our hypotheses. MacWhinney (2005) suggests that the closer the conceptual similarity of properties cross-linguistically, the more likely a successful positive transfer to a child's L2 will be. For consonant and syllable-structure patterns, the decreases we observed as well as the higher frequency of trill and tap errors are expected developmentally.
Further studies will need to be conducted to determine if rates of decrease are similar to those of monolingual or simultaneous bilingual children. A study including more children will be necessary to explore the variable rates of error observed for consonants and word structures; at this time, it is not possible to determine if the variability observed is typical or varies by age or bilingual language exposure. The significant decrease in cluster reduction observed suggests that children are progressing in their sequencing of consonants, a skill that is required in both English and Spanish.

In summary, these findings suggest that speech development in emerging sequential bilingual children may show effects of the new language on a child's first language. Statistically significant increases in Spanish vowel errors after English exposure suggest permeability of the L1 by the L2, at least temporarily. Further research of effects on L1 after L2 exposure is warranted to determine the time course of this effect of L2 on L1 phonology.

Appendix A. Spanish stimulus word list $\ddagger$

\begin{tabular}{|c|c|c|c|c|c|}
\hline $\begin{array}{l}\text { Spanish } \\
\text { word }\end{array}$ & $\begin{array}{l}\text { English } \\
\text { translation }\end{array}$ & $\begin{array}{l}\text { Phonetic } \\
\text { transcription(s)* }\end{array}$ & $\begin{array}{l}\text { Spanish } \\
\text { word }\end{array}$ & $\begin{array}{l}\text { English } \\
\text { translation }\end{array}$ & $\begin{array}{l}\text { Phonetic } \\
\text { transcription(s)* }\end{array}$ \\
\hline baño & bath & /báno/ & lapiz & pencil & /lápis/ \\
\hline basura & trash & /basúra/ & leche & milk & /lét $\int \mathrm{e} /$ \\
\hline bebé & baby & /beßé/ & llave & key & /jáße/ \\
\hline bicicleta & bicycle & /bisikléta/ & mano & hand & /máno/ \\
\hline bloques & blocks & /blókes/ & manzana & apple & /mansána/ \\
\hline boca & mouth & /bóka/ & martillo & hammer & /martijo/ \\
\hline botas & boots & /bótas/ & muñeca & doll & /munéka/ \\
\hline caballo & horse & /kaßájo/ & naríz & nose & /naris/ \\
\hline café & brown & /kafé/ & oso & bear & /óso/ \\
\hline casa & house & /kása/ & papá & father & /papá/ \\
\hline chico & little/boy & $/ \mathrm{t} \int \mathrm{iko} /$ & perro & $\operatorname{dog}$ & /péro/ \\
\hline coche & car & 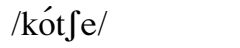 & plato & plate & /pláto/ \\
\hline cruz & cross & /krus/ & ratón & mouse & /ratón/ \\
\hline cuchara & spoon & 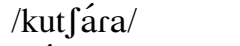 & relój & watch & /relóx/,/reló/ \\
\hline dedo & finger & /déðo/ & rojo & red & /róxo/ \\
\hline doctor & doctor & /dotó/, /dotór/ & sentado & sitting & /sentáðo/ \\
\hline dos & two & /dos/ & silla & chair & /sija/ \\
\hline elefante & elephant & /elefánte/ & sonrisa & smile & /sonrisa/ \\
\hline flores & flowers & /flóres/ & tijeras & scissors & /tixéras/ \\
\hline gato & cat & /gáto/ & tren & train & /tren/ \\
\hline huevo & egg & /wéßo/ & tres & three & /tres/ \\
\hline jabón & soap & /xaßón/ & uvas & grapes & /úßas/ \\
\hline jugo & juice & /xúyo/ & & & \\
\hline
\end{tabular}

$\ddagger$ Resources for many stimulus words were the Assessment of Phonological Disabilities - Spanish (Iglesias, 1978) and the Assessment of Phonological Processes - Spanish (Hodson, 1986).

*We show the most frequent pronunciations of the target words in Mexican Spanish; however, any pronunciation that represented correct pronunciation in a Mexican Spanish dialect was accepted as correct. 


\section{Appendix B. Phonological error patterns analyzed*}

SyLlABLE-LEVEL ERROR PATTERNS

- Cluster Deletion. The deletion of a consonant cluster sequence.

/plato/ "plate" $\rightarrow$ [ato $]$

- Cluster Reduction.* A consonant cluster sequence produced as a singleton consonant.

/tres/ "three" $\rightarrow$ [tes]

- Final Consonant Deletion. The deletion of any consonant phoneme in final word position.

$/$ pan/ "bread" $\rightarrow$ [pa]

- Initial Consonant Deletion.* The deletion of a consonant phoneme in initial word position.

/gato/ "cat" $\rightarrow$ [ato]

- Medial Consonant Deletion. Deletion of any consonant singleton phoneme in medial word position.

/teneðor/ "fork" $\rightarrow$ [teneor]

- Stressed Syllable Deletion. The deletion of a stressed syllable in a multisyllabic word.

/plátano/ "banana" $\rightarrow$ [tano]

- Unstressed Syllable Deletion. The deletion of an unstressed syllable in a multisyllabic word.

/plátano/ "banana" $\rightarrow$ [pláno]

\section{SEGMENTAL-LEVEL ERROR PATTERNS: CONSONANTS}

- Backing. A consonant produced further back in the oral cavity.

/plato/ "plate" $\rightarrow$ [plako]

- Fronting.* A consonant produced further forward in the oral cavity.

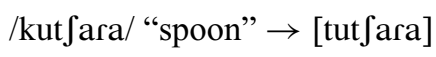

- Gliding. A liquid produced as a glide.

/lapis/ "pencil" $\rightarrow$ [japis]

- Glottal Substitution. Any consonant produced as a glottal stop.

/deðo/ "finger" $\rightarrow$ [?e?o]

- Liquid Simplification. A glide produced as a liquid. $/ \mathrm{we} \beta \mathrm{o} /$ "egg" $\rightarrow$ [le $\beta \mathrm{o}]$

- Nasal Stopping. A nasal consonant released orally. /mano/ "hand" $\rightarrow$ [bado]
- Spirantization. A non-fricative produced as a fricative "unless accurate allophonically for Spanish".

/gato/ "cat" $\rightarrow$ [gaso]

- Stopping. A fricative or affricate produced as a stop. /xaßon/ "soap" $\rightarrow$ [gaßon]

- Flap/Tap Error. A tap produced in error, typically as a stop or a trill.

/flores/ "flower" $\rightarrow$ [flodes] or [flores]

- Trill Error.* A trill produced in error, typically as a tap, liquid or stop.

$/$ pero/ "dog" $\rightarrow$ [pedo] or [pelo] or [pero]

- Vocalization. A liquid produced as a vowel or glide.

$/$ let $\int \mathrm{e} /$ "dog” $\rightarrow$ [jet $\left.\int \mathrm{e}\right]$

\section{SEGMENTAL-LEVEL ERROR PATTERNS: VOWELS}

- Front/Back Change - Small.* A front vowel produced as central, or central vowel produced as back, or vice versa

/pero/ "dog" $\rightarrow$ [p $\Lambda$ ro]; / xuro/ "juice" $\rightarrow$ [xtro]

- Front/Back Change - Large. A front vowel produced as a back vowel, or vice versa.

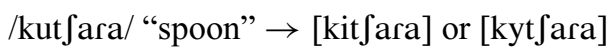

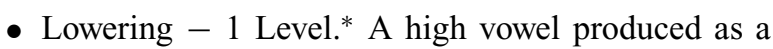
mid vowel, or a mid vowel produced as a low vowel.

/ußas/ "grapes" $\rightarrow$ [oßas]; /deðo/ "finger" $\rightarrow$ [dæðo]

- Raising - 1 Level. $^{*}$ A low vowel produced as mid, or a mid vowel produced as high.

$/$ dos/ "two" $\rightarrow[$ dus]; /kasa/ "house" $\rightarrow[$ kıs $\Lambda]$

*Error patterns statistically analyzed because they occurred at average rates of $4 \%$ or greater at Time $1 \mathrm{and} / \mathrm{or}$ Time 2 and changed by 2 percentage points or more from Time 1 to Time 2 .

\section{References}

Acevedo, M. A. (1993). Development of Spanish consonants in preschool children. Journal of Childhood Communication Disorders, 15 (2), 9-15.

Anderson, R. T. (2004). Phonological acquisition in preschoolers learning a second language via immersion: A longitudinal study. Clinical Linguistics and Phonetics, 18 (3), 183210.

Anderson, R. T. \& Smith, B. L. (1987). Phonological development of two-year-old monolingual Puerto Rican Spanish-speaking children. Journal of Child Language, 14 (1), 57-78. 
Baker, C. (2001). Foundations of bilingual education and bilingualism (3rd edn.). Clevedon: Multilingual Matters.

Boysson-Bardies, B. \& Vihman, M. M. (1991). Adaptation to language: Evidence from babbling and first words in four languages. Language, 67 (2), 297-319.

Bradlow, A. (1995). A comparative acoustic study of English and Spanish vowels. Journal of the Acoustical Society of America, 97 (3), 1916-1924.

Cohen, J. (1988). Statistical power analysis for the behavioral sciences (2nd edn.). Hillsdale, NJ: Lawrence Erlbaum.

Davis, B. \& MacNeilage, P. F. (1995). The articulatory basis of babbling. Journal of Speech and Hearing Research, 38 (6), 1199-1211.

Döpke, S. (2000). Generation of and retraction from cross-linguistically motivated structures in bilingual first language acquisition. Bilingualism: Language \& Cognition, 3 (3), 209-226.

Gardner, M. F. (1985). Receptive one-word picture vocabulary test. Novato, CA: Academic Therapy Publications.

Gardner, M. F. (1990). Expressive one-word picture vocabulary test (Revised). Novato, CA: Academic Therapy Publications.

Genesee, F. (1989). Early bilingual development: One language or two? Journal of Child Language, 16 (1), 161-179.

Gildersleeve-Neumann, C. E. (2001). Constraints on infant speech acquisition: A cross-language perspective. Ph.D. dissertation, University of Texas at Austin. [Dissertation Abstracts International, 62, 11.]

Gildersleeve-Neumann, C. E., Kester, E. S., Davis, B. L. \& Peña, E. D. (2008). English speech sound development in preschool-aged children from English-Spanish environments. Language, Speech, and Hearing Services in Schools, 39 (3), 314-328.

Goldstein, B. (2001). Transcription of Spanish and Spanishinfluenced English. Communication Disorders Quarterly, 23 (1), 54-60.

Goldstein, B. (2004). Bilingual language development and disorders in Spanish-English speakers. Baltimore, MD: Brookes Publishing.

Goldstein, B. \& Cintrón, P. (2001). An investigation of phonological skills in Puerto Rican Spanish-speaking 2year-olds. Clinical Linguistics \& Phonetics, 15 (5), $343-$ 361.

Goldstein, B. \& Iglesias, A. (1996). Phonological patterns in Puerto Rican Spanish-speaking children with phonological disorders. Journal of Communication Disorders, 29 (5), 367-387.

Goldstein, B. \& Pollock, K. E. (2000). Vowel errors in Spanish-speaking children with phonological disorders: A retrospective comparative study. Clinical Linguistics \& Phonetics, 14 (3), 217-234.

Goldstein, B. \& Washington, P. (2001). An initial investigation of phonological patterns in typically developing 4-year-old Spanish-English bilingual children. Language, Speech, and Hearing Services in Schools, 32 (3), 153-164.

Grosjean, F. (1989). Neurolinguists, beware! The bilingual is not two monolinguals in one person. Brain and Language, 36 (1), 3-15.

Hodson, B. W. (1986). Assessment of Phonological Processes Spanish. San Diego, CA: Los Amigos Research Associates.
Holm, A. \& Dodd, B. (1999). A longitudinal study of the phonological development of two Cantonese-English bilingual children. Applied Psycholinguistics, 20 (3), 349376.

Iglesias, A. (1978). Assessment of Phonological Disabilities Spanish. [Unpublished assessment tool.]

Jimenez, B. C. (1987). Acquisition of Spanish consonants in children aged 3-5 years, 7 months. Language, Speech, and Hearing Services in Schools, 18 (4), 357-363.

Johnson, C. E. \& Lancaster, P. (1998). The development of more than one phonology: A case study of a NorwegianEnglish child. The International Journal of Bilingualism, 2 (3), 265-300.

Kehoe, M. M. (2002). Developing vowel systems as a window to bilingual phonology. The International Journal of Bilingualism, 6 (3), 315-334.

Kehoe, M. [M.] \& Lleó, C. (2003). The acquisition of syllable types in monolingual and bilingual German- and Spanishspeaking children. Proceedings of the 27th Annual Boston University Conference on Language Development, 27 (1), 402-413.

Kester, E. S., Peña, E. D. \& Gillam, R. B. (2001). Outcomes of dynamic assessment with culturally and linguistically diverse students: A comparison of three teaching methods. Journal of Cognitive Education and Psychology. 2 (1), 4259.

Linares, T. A. (1981). Articulation skills in Spanish-speaking children. In R. V. Padilla (ed.), Ethnoperspectives in bilingual education research: Bilingual education technology (Ethnoperspectives in Bilingual Education), pp. 363-376. Ypsilanti, MI: Eastern Michigan University, Bilingual Programs.

MacNeilage, P. F., Davis, B. L., Kinney, A. \& Matyear, C. L. (2000). The motor core of speech: A comparison of serial organization patterns in infants and languages. Child Development, 71 (1), 153-163.

MacWhinney, B. (2005). A unified model of language acquisition. In J. F. Kroll \& A. M. B. De Groot (eds.), Handbook of bilingualism: Psycholinguistic approaches, pp. 49-67. Oxford: Oxford University Press.

Maddieson, I. (1984). Patterns of sounds. Cambridge: Cambridge University Press.

McLaughlin, B. (1984). Second language acquisition in childhood. Somerset, NJ: John Wiley and Sons.

Morales-Front, A. (2007). Acquisition of syllable structure in Spanish. In F. Martínez-Gil \& S. Colina (eds.), Optimality-theoretic studies in Spanish phonology, 497524. Philadelphia, PA: John Benjamins.

Nuñez-Cedeño, R. (2007). The acquisition of Spanish codas: A frequency/sonority approach. Hispania, 90, 147-163.

Oller, D. K. \& Delgado, R. (2000). Logical International Phonetics Program (Version 2.02). Miami, FL: Intelligent Hearing Systems. [Software program.]

Oller, D. K. \& Eilers, R. E. (1982). Similarity of babbling in Spanish- and English-learning babies. Journal of Child Language, 9 (3), 565-577.

Paradis, J. (2005). Grammatical morphology in children learning English as a second language: Implications of similarities with specific language impairment. Language, Speech, and Hearing Services in Schools, 36 (3), 172-187. 
Porter, J. H. \& Hodson, B. W. (2001). Collaborating to obtain phonological acquisition data for local schools. Language, Speech, and Hearing Services in Schools, 32 (3), 162171.

Shriberg, L. D. (1993). Four new speech and prosody-voice measures for genetics research and other studies in developmental phonological disorder. Journal of Speech and Hearing Research, 36 (1), 105-140.

Shriberg, L. D., Austin, D., Lewis, B., McSweeney, J. \& Wilson, D. (1997). The percentage of consonants correct (PCC) metric: Extensions and reliability data. Journal of Speech, Language, and Hearing Research, 40 (4), 708722.

Stoel-Gammon, C. \& Dunn, J. (1985). Normal phonological development. In C. Stoel-Gammon \& J. Dunn (eds.), Normal and disordered phonology in children, pp. 15-46. Baltimore, MD: University Park Press.
Stoel-Gammon, C. \& Herrington, P. (1990). Vowel systems of normally developing and phonologically disordered children. Clinical Linguistics \& Phonetics, 4 (2), 145-160.

Thorndike, R. L., Hagen, E. P. \& Sattler, J. M. (1986). StanfordBinet intelligence scale: Fourth edition. Chicago, IL: Riverside.

Vihman, M. M., Ferguson, C. A. \& Elbert, M. (1986). Phonological development from babbling to speech: Common tendencies and individual differences. Applied Psycholinguistics, 7 (1) 3-40.

Yavaş, M. \& Goldstein, B. (1998). Phonological assessment and treatment of bilingual speakers. American Journal of Speech-Language Pathology, 7 (2), 49-60.

Received: March 9, 2007

Final revision received: March 3, 2008

Accepted: March 13, 2008 